Editor's Note: These short reviews of recent JNeurosci articles, written exclusively by students or postdoctoral fellows, summarize the important findings of the paper and provide additional insight and commentary. If the authors of the highlighted article have written a response to the Journal Club, the response can be found by viewing the Journal Club at www.jneurosci.org. For more information on the format, review process, and purpose of Journal Club articles, please see http://jneurosci.org/content/ preparing-manuscript\#journalclub.

\title{
Enhancing Memory Consolidation through Slow Oscillation and Spindle Synchronization
}

\author{
Sara Y. Kim, ${ }^{1}$ Enmanuelle Pardilla-Delgado, ${ }^{1,2}$ and Sara E. Alger ${ }^{1}$ \\ ${ }^{1}$ University of Notre Dame, Department of Psychology, Cognition, Brain, and Behavior Program, Notre Dame, Indiana 46556, and 2Massachusetts General \\ Hospital/Harvard School of Medicine, Department of Psychiatry, Charlestown, Massachusetts 02129 \\ Review of Ladenbauer et al.
}

Declines in sleep quality and cognitive function, particularly the formation and retention of hippocampal-dependent memories, are hallmarks of neurodegenerative disorders, such as Alzheimer's disease (AD). These events might be related: converging evidence suggests that sleep plays an active role in memory consolidation, with nonrapid eye movement (NREM) sleep particularly benefiting declarative memories (Ellenbogen et al., 2006). In particular, cortical slow oscillations ( $\mathrm{SO} ; 0.5-1 \mathrm{~Hz}$ ), thalamocortical sleep spindles (slow: 8-12 $\mathrm{Hz}$, fast: 12-15 Hz), and hippocampal sharp wave-ripples (SPW-R; 80-100 Hz), EEG events that characterize NREM sleep, have been shown to facilitate hippocampaldependent memory consolidation in both rodents (Ji and Wilson, 2007) and humans (Tamminen et al., 2010).

Mounting evidence demonstrates that the coordination of NREM sleep oscillations underlies systems-level consolidation of information from the hippocampus to long-term stores in the neocortex (Clemens et al., 2011; Staresina et al., 2015). Therefore, the functional interaction between slow oscillations and sleep spindles is crucial to consider, and current theory regarding

Received Sept. 1, 2017; revised 0ct. 16, 2017; accepted 0ct. 20, 2017. The authors declare no competing financial interests.

Correspondence should be addressed to Sara Y. Kim, University of Notre Dame, B24 Haggar Hall, Notre Dame, IN 46556. E-mail: skim39@nd.edu. DOI:10.1523/JNEUROSCI.2512-17.2017

Copyright $\odot 2017$ the authors $\quad 0270-6474 / 17 / 3711517-03 \$ 15.00 / 0$ sleep-dependent consolidation takes this coupling into account (Rasch and Born, 2013). Slow oscillations and spindles are phase-coupled during NREM sleep. Spindles are suppressed during hyperpolarized SO down-states but rebound during the depolarizing SO up-states. Spindles are also temporally related to SPW-R, with ripples nested into the troughs of fast spindles, creating spindle-ripple events (Clemens et al., 2011). This temporal coupling of SO, spindles, and SPW-R might be involved in reactivation of hippocampal-dependent memories and consolidation of the memories within neocortical sites.

In human research, noninvasive brain stimulation techniques have emerged as a critical tool to test the causal, as opposed to correlational, relationship between SO, spindle activity, and memory consolidation by allowing modulation of these EEG events during sleep. However, research using transcranial direct-current stimulation (tDCS) has largely studied SO and spindles in isolation, and studies have provided inconsistent data on the benefits of SO and spindles in hippocampal-dependent memory (e.g., Marshall et al., 2006; Paßmann et al., 2016). Moreover, research to date has largely focused on healthy populations, raising the question of how $\mathrm{SO}$, spindles, and their functional coupling affect memory consolidation in neurodegenerative disease.
In a recent publication, Ladenbauer et al. (2017) addressed this question in patients with mild cognitive impairment (MCI), a precursor to $\mathrm{AD}$ and other neurological disorders. The authors applied slow oscillatory tDCS (so-tDCS) intermittently to frontal locations during NREM sleep as participants napped. They then examined so-tDCS-related effects on visuospatial, verbal, and procedural memory. Of particular interest was visuospatial memory, which primarily involves the hippocampus and surrounding areas and is affected in MCI (Barbeau et al., 2004). Participants viewed 38 neutral, complex pictures in one of four quadrants and were instructed to memorize both the picture and its location. Either so-tDCS or sham stimulation was applied during the subsequent 90 min nap. Importantly, stimulation was individualized to each participant's sleep to account for sleep fragmentation, such that each stimulation-free interval was prolonged if a participant moved out of NREM sleep.

To determine temporal relationships between SO and fast spindle power, the authors assessed SO-to-spindle phaseamplitude coupling (PAC). PAC examines temporal synchronization between oscillations in any two related regions (Fell and Axmacher, 2011), including dependencies between high- and low-frequency oscillations (cross-frequency coupling). Ladenbauer et al. (2017) found that so- 
tDCS enhanced this coupling, with greater SO-fast spindle synchrony and fast spindle power during SO up-phases. Notably, this functional coupling may have been critical for the reported beneficial impact of so-tDCS on memory: although neither SO nor spindle activity alone correlated with memory performance, SO and fast spindle synchrony in the so-tDCS condition were associated with improved visual recognition.

PAC has been understudied in the SO and spindle frequency ranges, despite evidence that spindles and SPW-R are grouped by SO up-states to facilitate consolidation of episodic memories (Ji and Wilson, 2007). Ladenbauer et al. (2017) directly investigated the possibility that PAC drives SOand spindle-related benefits for declarative memory. These findings add to growing evidence of the importance of cross-frequency coupling in various types of memory. Phaselocking of theta $(4-7 \mathrm{~Hz})$ and gamma (30$100 \mathrm{~Hz}$ ) frequencies in the hippocampus, for example, have been shown to increase learning of item-context associations in rats (Tort et al., 2009), as well as working memory performance in humans (Fell and Axmacher, 2011). Theta-gamma coupling in the prefrontal cortex is also correlated with spatial working memory in humans, and these benefits appear to be critically dependent on such coupling (Alekseichuk et al., 2016).

The work by Ladenbauer et al. (2017) is of particular relevance for neurodegenerative disorders characterized by memory and sleep impairments, such as MCI and AD. Cognitive decline in $\mathrm{AD}$ has been associated with atrophy of brain structures important for the generation of $\mathrm{SO}$, spindles, and SPW-R, including the hippocampus and thalamus (Mouton et al., 1998; de Jong et al., 2008). Impaired SO and spindle generation may contribute to the severe memory impairments seen in $\mathrm{AD}$. Reduced gray matter and amyloid- $\beta$ deposition in the medial prefrontal cortex have been associated with reduced NREM slow-wave activity $(<1 \mathrm{~Hz})$ and reduced functional connectivity between the hippocampus and prefrontal cortex (Mander et al., 2013, 2015). Importantly, these reductions predict reduced overnight memory retention, suggesting that disruptions in spindles and SO contribute to rapid memory declines in neurodegenerative disorders.

Disruptions in PAC, rather than SO and spindle dysregulation alone, might be an important consideration in neurodegenerative disorders. Spindle synchrony across the thalamus and cortex is dependent on active corticothalamic input, and atrophy in these regions may impair PAC. GABAergic neurons of the thalamic reticular nucleus impart rhythmic IPSPs onto thalamocortical neurons, which in turn fire spindlefrequency excitatory input to the cortex (Neske, 2015). Animal research has demonstrated that removal of cortex disrupts synchronization of SO and spindles (Contreras et al., 1996), suggesting that cortical atrophy impairs PAC. Further, the thalamic reticular nucleus communicates with structures in the brainstem and parts of the limbic thalamus, regions that are known to be affected in AD (Braak and Braak, 1991). Therefore, it is possible that AD-related atrophy of cortical and thalamic regions reduces SO-to-spindle coupling in neurodegenerative disorders.

Understanding the role of PAC in memory consolidation may be the next critical step in uncovering the underlying causes of sleep-related cognitive decline. Research has consistently shown that memory-relevant electrophysiological coherence is impaired in $\mathrm{MCI} / \mathrm{AD}$ during wake (Hogan et al., 2003; Bazzigaluppi et al., 2017), and research on SO and spindles raise the possibility that similar impairments occur during sleep and lead to sleep-dependent memory consolidation impairments. The findings of Ladenbauer et al. (2017) suggest that so-tDCS may be an avenue for individualized treatment of memory decline by modulating SO-tospindle PAC.

Although Ladenbauer et al. (2017) focus on the coupling of specific sleep parameters, future work might also consider possible interactions with factors such as sleep quality. For example, sleep fragmentation is common in older adults and magnified in MCI (Lim et al., 2013). It has been shown to impair LTP and learning in rodents (Wallace et al., 2015). Importantly, increased sleep continuity (i.e., less fragmentation) has been associated with improved declarative learning in healthy older adults (Gosselin et al., 2016). To minimize sleep fragmentation in their study, Ladenbauer et al. (2017) individualized stimulation to each participant's sleep. In this study, so-tDCS increased Stage 2 and marginally decreased Stage 1 (light) sleep as well as wake after sleep onset. Interestingly, these changes in sleep architecture did not correlate with visual memory performance. Nonetheless, so-tDCS may still have decreased sleep fragmentation. In turn, enhanced sleep continuity could have benefited visual memory performance independently from SO-to-spindle PAC. Therefore, future research should consider whether brain stimulation not only increases individual events, such as spindles or $\mathrm{SO}$, or coherence between events, but also sleep quality as a whole.

The findings of Ladenbauer et al. (2017) further our understanding of sleep-dependent memory consolidation, including a lesser-examined feature of sleep (i.e., phaseamplitude coupling) that may be critical for hippocampal-dependent memory consolidation. While SO and spindles on their own have been related to memory performance, the specific association of PAC with improved visual recognition suggests that functional coupling may be vital for effective reactivation and consolidation of information during sleep. Future work should aim to develop an intervention strategy using noninvasive brain stimulation methods, such as tDCS, for individualized treatment of sleep and memory impairments. Enhancing SO and spindle synchronization provides promising future directions for benefitting sleep and memory processes in neurodegenerative disorders, such as $\mathrm{AD}$, that are characterized by dysregulated sleep and impaired sleep-dependent memory consolidation.

\section{References}

Alekseichuk I, Turi Z, Amador de Lara G, Antal A, Paulus W (2016) Spatial working memory in humans depends on theta and high gamma synchronization in the prefrontal cortex. Curr Biol 26:1513-1521. CrossRef Medline

Barbeau E, Didic M, Tramoni E, Felician O, Joubert S, Sontheimer A, Ceccaldi M,Poncet M (2004) Evaluation of visual recognition memory in MCI patients. Neurology 62:1317-1322. CrossRef Medline

Bazzigaluppi P, Beckett TL, Koletar MM, Lai AY, Joo IL, Brown ME, Stefanovic B (2017) Early stage attenuation of phase amplitude coupling in the hippocampus and medial prefrontal cortex in a transgenic rat model of AD. J Neurochem. Advance online publication. Retrieved Aug. 4, 2017. doi: 10.1111/jnc. 14136. CrossRef Medline

Braak H, Braak E (1991) Neuropathological stageing of Alzheimer-related changes. Acta Neuropathol 82:239-259. CrossRef Medline

Clemens Z, Mölle M, Eross L, Jakus R, Rásonyi G, Halász P, Born J (2011) Fine-tuned coupling between human parahippocampal ripples and sleep spindles. Eur J Neurosci 33:511-520. CrossRef Medline

Contreras D, Destexhe A, Sejnowski TJ, Steriade M (1996) Control of spatiotemporal coherence of a thalamic oscillation by corticothalamic feedback. Science 274:771-774. CrossRef Medline

de Jong LW, van der Hiele K, Veer IM, Houwing JJ, Westendorp RG, Bollen EL, de Bruin PW, Middelkoop HA, van Buchem MA, van der Grond J (2008) Strongly reduced volumes of putamen and thalamus in Alzheimer's disease: an MRI study. Brain 131:3277-3285. CrossRef Medline

Ellenbogen JM, Payne JD, Stickgold R (2006) The role of sleep in declarative memory consolidation: passive, permissive, active or none? 
Curr Opin Neurobiol 16:716-722. CrossRef Medline

Fell J, Axmacher N (2011) The role of phase synchronization in memory processes. Nat Rev Neurosci 12:105-118. CrossRef Medline

Gosselin N, De Beaumont L, Gagnon K, Baril AA, Mongrain V, Blais H, Montplaisir J, Gagnon JF, Pelleieux S, Poirier J, Carrier J (2016) BDNF Val66Met polymorphism interacts with sleep consolidation to predict ability to create new declarative memories. J Neurosci 36:83908398. CrossRef Medline

Hogan MJ, Swanwick GR, Kaiser J, Rowan M, Lawlor B (2003) Memory-related EEG power and coherence reductions in mild Alzheimer's disease. Int J Psychophysiol 49:147-163. CrossRef Medline

Ji D, Wilson MA (2007) Coordinated memory replay in the visual cortex and hippocampus during sleep. Nat Neurosci 10:100-107. CrossRef Medline

Ladenbauer J, Ladenbauer J, Külzow N, de Boor R, Avramova E, Grittner U, Flöel A (2017) Promoting sleep oscillations and their functional coupling by transcranial stimulation enhances memory consolidation in mild cognitive impairment. J Neurosci 37:7111-7124. CrossRef Medline

Lim AS, Kowgier M, Yu L, Buchman AS, Bennett DA (2013) Sleep fragmentation and the risk of incident Alzheimer's disease and cognitive decline in older persons. Sleep 36:1027-1032. CrossRef Medline

Mander BA, Rao V, Lu B, Saletin JM, Lindquist JR, Ancoli-Israel S, Jagust W, Walker MP (2013) Prefrontal atrophy, disrupted NREM slow waves and impaired hippocampal-dependent memory in aging. Nat Neurosci 16:357-364. CrossRef Medline

Mander BA, Marks SM, Vogel JW, Rao V, Lu B, Saletin JM, Ancoli-Israel S, Jagust WJ, Walker MP (2015) [beta]-amyloid disrupts human NREM slow waves and related hippocampusdependent memory consolidation. Nat Neurosci 18:1051-1057. CrossRef Medline

Marshall L, Helgadóttir H, Mölle M, Born J (2006) Boosting slow oscillations during sleep potentiates memory. Nature 444:610-613. CrossRef Medline

Mouton PR, Martin LJ, Calhoun ME, Dal Forno G, Price DL (1998) Cognitive decline strongly correlates with cortical atrophy in Alzheimer's dementia. Neurobiol Aging 19:371-377. CrossRef Medline

Neske GT (2015) The slow oscillation in cortical and thalamic networks: mechanisms and functions. Front Neural Circuits 9:88. CrossRef Medline

Paßmann S, Külzow N, Ladenbauer J, Antonenko D, Grittner U, Tamm S, Flöel A (2016) Boost- ing slow oscillatory activity using tDCS during early nocturnal slow wave sleep does not improve memory consolidation in healthy older adults. Brain Stimul 9:730-739. CrossRef Medline

Rasch B, Born J (2013) About sleep's role in memory. Physiol Rev 93:681-766. CrossRef Medline

Staresina BP, Bergmann TO, Bonnefond M, van der Meij R, Jensen O, Deuker L, Elger CE, Axmacher N, Fell J (2015) Hierarchical nesting of slow oscillations, spindles and ripples in the human hippocampus during sleep. Nat Neurosci 18:1679-1686. CrossRef Medline

Tamminen J, Payne JD, Stickgold R, Wamsley EJ, Gaskell MG (2010) Sleep spindle activity is associated with the integration of new memories and existing knowledge. J Neurosci 30: 14356-14360. CrossRef Medline

Tort AB, Komorowski RW, Manns JR, Kopell NJ, Eichenbaum H (2009) Theta-gamma coupling increases during the learning of itemcontext associations. Proc Natl Acad Sci U S A 106:20942-20947. CrossRef Medline

Wallace E, Kim DY, Kim KM, Chen S, Blair Braden B, Williams J, Jasso K, Garcia A, Rho JM, Bimonte-Nelson H, Maganti R (2015) Differential effects of duration of sleep fragmentation on spatial learning and synaptic plasticity in pubertal mice. Brain Res 1615: 116-128. CrossRef Medline 